\title{
Seasonal hospitalization in patients with mood disorder
} Athanasios Karkanias*1, Georgios Moussas ${ }^{2}$, Argiro Pachi ${ }^{1}$, Kalliopi VassilaDemi $^{1}$, Dionisios Bratis ${ }^{1}$ and Athanasios Tselebis ${ }^{1}$

\author{
Address: "Psychiatric Department, "Sotiria" General Hospital, Athens, Greece and 2Second Psychiatric Department, "Attikon" General Hospital, \\ University of Athens, Greece \\ ${ }^{*}$ Corresponding author
}

from International Society on Brain and Behaviour: 3rd International Congress on Brain and Behaviour

Thessaloniki, Greece. 28 November - 2 December 2007

Published: 17 April 2008

Annals of General Psychiatry 2008, 7(Suppl I):SI 92 doi:I0.II86/I744-859X-7-SI-SI 92

This abstract is available from: http://www.annals-general-psychiatry.com/content/7/SI/SI 92

(c) 2008 Karkanias et al.; licensee BioMed Central Ltd.

\section{Background}

Several studies have indicated the participant role of the season of the year as a factor of manifestation of mood disorders. Furthermore, although the seasonal pattern of admissions of patients with mood disorders have been extensively studied in international bibliography, just few relative references are present in Greece. The objective of this study is to investigate the seasonal necessity of hospitalization in Greek patients with mood disorders.

\section{Materials and methods}

The demographic characteristics of 448 inpatients diagnosed with mood disorder during a four years' period were reviewed. We specifically recorded sex, age, duration of hospitalization, season of admission and the number of patients hospitalized involuntary.

\section{Results}

Females were statistically more $(\mathrm{x} 2 \mathrm{p}<0.05)$ than males $(60.9 \%$ vs $39.1 \%)$. Mean age of the sample was 44.7 years $( \pm 13.61)$ whereas mean duration of hospitalization was 18.85 days $( \pm 16.74)$. Age and duration of hospitalization doesn't seem to differentiate as to sex (t test $\mathrm{p}>0.05$ ). The number of involuntarily hospitalized patients doesn't differentiate as to season of admission ( $\mathrm{x} 2 \mathrm{p}>0.05)$ however we observed an increase of admissions of voluntarely hospitalized male patients in spring $(\mathrm{x} 2 \mathrm{p}<0.05)$. Finally, the duration of hospitalization is not influenced by season of admission. Also, the age factor is indipendent to the season of hospitalization (ANOVA p $>0.05$ ).

\section{Conclusions}

The results report an increase of necessity of hospitalizations in patients with mood disorders in spring, a finding which is in agreement with relevant international studies. Increased sunlight or environmental temprature may be risk factors. Further studies are required in order to investigate if these findings are related to weather conditions or other risk factors.

\section{References}

I. D' Mello DA, McNeil JA, Msibi B: Seasons and bipolar disorder. Ann Clin Psychiatry 1995, 7(1): I I-8.

2. Morken G, Lilleeng S, Linaker OM: Seasonal variation in suicides and in admissions to hospital for mania and depression. J Affect Disord 2002, 69(1-3):39-45. 